\title{
Clinical characteristics and analysis of risk factors for disease progression of COVID-19: A retrospective Cohort Study
}

\author{
Zhengtong $\mathrm{Lv}^{1,2 \bowtie}$ and Shubin $\mathrm{Lv}^{3 凶}$ \\ 1. Beijing Hospital, National Center of Gerontology; Institute of Geriatric Medicine, Chinese Academy of Medical Sciences, P.R. China \\ 2. Graduate School of Peking Union Medical College and Chinese Academy of Medical Sciences, P.R. China. \\ 3. Department of Respiratory Medicine, Tianjin Binhai New Area Dagang Hospital, Tianjin, P.R. China. \\ *These two authors contributed equally to this article.
}

$\triangle$ Corresponding authors: Zhengtong Lv, Beijing Hospital, No. 1 DaHua Road, Dong Dan, Beijing, 100730, China. E-mail: lvzhengtong@88.com; Shubin Lv, Department of Respiratory Medicine, Tianjin Binhai New Area Dagang Hospital, No.1200 Dagang Nanhuan Road, Tianjin Binhai New Area, Tianjin, 300270 , China. E-mail: 83730692@qq.com.

(C) The author(s). This is an open access article distributed under the terms of the Creative Commons Attribution License (https://creativecommons.org/licenses/by/4.0/). See http://ivyspring.com/terms for full terms and conditions.

Received: 2020.07.14; Accepted: 2020.10.04; Published: 2021.01.01

\begin{abstract}
Objective: Since December 2019, an outbreak of coronavirus disease 2019 (COVID 19) has been experienced from Wuhan, China to the world. A retrospective cohort study was conducted to summarize the clinical characteristics of patients with COVID-19 and to explore the risk factors affecting the disease duration in Jiangan Fangcang shelter hospital, Wuhan, China.

Methods: Clinical characteristics of 409 patients with COVID-19 were retrospectively analyzed. We describe the clinical characteristics and distribution of discharge time or transfer time for each patient. Then we performed univariate and multivariate Cox regression analysis to identify potential risk factors for progression from non-severe to severe COVID-19 or death.

Results: The median disease duration of all patients was 23 days (IQR 19-28). The main symptoms of the patient were fever $(95.6 \%)$, cough $(74.3 \%)$, tiredness $(21.5 \%)$, and so on. Comorbidities mainly included hypertension $(30.6 \%)$ diabetes $(17.6 \%)$ and heart disease $(12.5 \%)$. The univariate Cox regression analysis showed that old age, number of symptoms, the combination of hypertension, heart disease and pulmonary disease were associated with the progression of disease. The multivariate Cox regression analysis showed that old age (HR: 7.294; 95\% Cl: 1.442-36.888; $P=0.016$ ), the combination of hypertension (HR: $2.230 ; 95 \% \mathrm{Cl}$ : $1.090-4.562 ; P=0.028)$ and heart disease (HR: $2.650 ; 95 \% \mathrm{Cl}: 1.079-6.510 ; P=0.034)$ were independent risk factors for progression of COVID-19.
\end{abstract}

Conclusions: The age of the patient, the combination of hypertension and heart disease were independent risk factors for the progression of COVID-19. Cautions should be raised for patients with these risk factors.

Key words: COVID-19; SARS-CoV-2; clinical characteristics; risk factors

\section{Introduction}

In December 2019, an unexplained pneumonia outbreak occurred in Wuhan, Hubei province, China [1]. On January 7, Chinese scientists isolated a novel coronavirus from pneumonia patients infected with these viruses, officially called the severe acute respiratory syndrome coronavirus 2 (SARS-CoV-2) [2]. Since the WHO emergency committee declared it a global health emergency, more than 200 countries have reported coronavirus disease 2019 (COVID-19).

After COVID-19 infection, the patients were characterized by fever, cough, dyspnea, bilateral lung infiltration, and acute respiratory injury [3-5]. Up to now, most studies have focused on the prevention and treatment of severe patients, which may develop into respiratory failure or even death [6]. However, according to epidemiological investigation, only $20 \%$ of the total number of patients are seriously ill, most of whom are non-severe COVID-19 patients (about $80 \%$ ) [7]. In view of the strong infectivity of SARSCoV-2, effective treatment of non-severe COVID-19 
patients is an important means to prevent the conversion of such patients to severe COVID-19 and even death, which is conducive to reversing the overload of hospitals and preventing the large-scale spread of the epidemic.

To this end, the Chinese government has set up 14 Fangcang shelter hospitals in Wuhan for the treatment of non-severe COVID-19 patients [8]. In this study, we retrospectively analyzed the COVID-19 patients in Wuhan Jiangan Fangcang shelter hospital to explored the risk factors that affected the duration of the disease, so as to formulate individualized preventive and therapeutic methods in advance for high-risk patients, take effective preventive measures as soon as possible, and prevent them from turning to severe or death cases.

\section{Methods}

\section{Study design and participants}

This study was a retrospective cohort study, which included COVID-19 patients in zone B and zone $\mathrm{C}$ of Wuhan Jiangan Fangcang shelter hospital from February 2020 to March 2020. Wuhan Jiangan Fangcang shelter hospital was managed by workers of Tianjin national medical team. This study was approved by the institutional ethics board of Tianjin national medical team. Written informed consent was waived by the institutional ethics board of the hospital, but oral consent was obtained from all the patients. This study was strictly reported according to STROBE statement.

\section{Inclusion criteria, exclusion criteria and other criteria}

The inclusion criteria were as follows: (1) all patients were confirmed to be COVID-19 by nucleic acid testing; (2) the disease types were non-severe, including mild (with mild clinical symptoms and no pneumonia on imaging) and common (with fever, respiratory tract infection and other symptoms, and pneumonia on imaging); (3) all clinical data required for the study were complete; (4) adults over 18 years old. The exclusion criteria were as follows: (1) patients who have not been confirmed by nucleic acid testing; (2) the disease types were severe at the time of diagnosis; (3) patients with incomplete clinical data. (4) The patient has a mental illness or other condition that affects their insight. In addition, Table 1 showed the criteria of patient admission, the criteria of transfer and the criteria of discharge of Fangcang shelter hospital.

\section{Treatment}

The general treatment included bed rest, support treatment, symptomatic treatment, sufficient heat, psychological guidance and masks for all patients during hospitalization. After assessment by the responsible doctor, patients with $\mathrm{SpO} 2 \leq 95 \%$ would be given nasal catheter oxygen. Antiviral drugs mainly included Abidol and Oseltamivir. In case of suspected bacterial infection, antibiotics including Cefdinir, Moxifloxacin, Levofloxacin and Azithromycin could be used or treatment. Patients could also receive traditional Chinese medicine treatment, such as Qingfei paidutang. If the patient had fever, physical cooling was recommended firstly. If the temperature was more than $38.5{ }^{\circ} \mathrm{C}$, the patient could take medicine to cool down as appropriate (such as Ibuprofen).

Table 1. The criteria of patient admission, the criteria of transfer and the criteria of discharge of Fangcang shelter hospital

\begin{tabular}{|c|c|c|c|}
\hline No. & Admission criteria & Transfer criteria & Discharge criteria \\
\hline 1 & $\begin{array}{l}\text { Mild signs or symptoms (mild clinical symptoms, imaging shows } \\
\text { no signs of pneumonia) to moderate signs or symptoms (fever, } \\
\text { respiratory tract symptoms, imaging shows pneumonia). }\end{array}$ & $\begin{array}{l}\text { Respiratory distress, breathing rate } \geq 30 \\
\text { beats per min }\end{array}$ & $\begin{array}{l}\text { The body temperature is normal for more } \\
\text { than } 3 \text { days. }\end{array}$ \\
\hline 2 & Have the ability to live and walk independently. & $\mathrm{SpO} 2 \leq 93 \%$ in resting state. & $\begin{array}{l}\text { Respiratory symptoms improved } \\
\text { significantly. }\end{array}$ \\
\hline 3 & $\begin{array}{l}\text { No severe chronic diseases, including heart, liver, lung, kidney, } \\
\text { brain and other important organ diseases. }\end{array}$ & $\begin{array}{l}\mathrm{PaO} 2 / \mathrm{FiO} 2 \leq 300 \mathrm{mmHg} \\
(1 \mathrm{mmHg}=0.133 \mathrm{kPa}) .\end{array}$ & $\begin{array}{l}\text { Imaging showed significant absorption of } \\
\text { lung inflammation. }\end{array}$ \\
\hline 4 & No history of mental illness. & $\begin{array}{l}\text { After treatment, the body temperature } \\
\text { remained above } 38.5^{\circ} \mathrm{C} \text { for more than } 2 \\
\text { days. }\end{array}$ & $\begin{array}{l}\text { Negative test of respiratory virus nucleic } \\
\text { acid for } 2 \text { consecutive times (sampling } \\
\text { interval of at least } 1 \text { day). }\end{array}$ \\
\hline 5 & SpO2 $>93 \%$ and breathing rate $<30$ beats per min in resting state. & $\begin{array}{l}\text { Have severe chronic diseases, including } \\
\text { heart, liver, lung, kidney, brain and other } \\
\text { important organ diseases (also including } \\
\text { hemodialysis patients). }\end{array}$ & $\begin{array}{l}\text { Without additional oxygen absorption, } \\
\text { SpO2 }>95 \% \text {. }\end{array}$ \\
\hline 6 & Other cases need special explanation. & No independent living ability. & $\begin{array}{l}\text { The duration of the disease has exceeded } \\
14 \text { days. }\end{array}$ \\
\hline 7 & & Suffering from mental illness, mania, etc. & \\
\hline 8 & & Other cases need special explanation. & \\
\hline Note: & All the above conditions must be met at the same time. & $\begin{array}{l}\text { Patients who meet one of the above } \\
\text { criteria will be transferred. }\end{array}$ & $\begin{array}{l}\text { All the above conditions must be met at } \\
\text { the same time. }\end{array}$ \\
\hline
\end{tabular}




\section{Outcomes}

The disease duration of all patients was recorded (The disease duration defined as from the onset of symptoms to the end of discharge). The basic clinical features, comorbidities and CT findings were also recorded. The primary outcome is the risk factors for progression from non-severe to severe COVID-19 or death.

\section{Data collection}

All patients were asked to fill in simple admission records before admission. All clinical characteristics of patients were obtained by collecting these admission records. The discharge date of all patients was recorded every day. By investigating the original records, the patient's disease duration time could be obtained from the time of symptom onset to the time of patient discharge.

\section{Sample size calculation}

In this study, univariate and multivariate Cox regression analysis were performed to determine the independent effect of risk factors for progression from non-severe to severe COVID-19 or death. For sample size estimation, at least 10 samples are generally required as events per variable [9]. There were 17 independent variables in this study, so each group needed at least 170 cases, and the total sample size needed at least 340 cases.

\section{Statistical analysis}

Frequency and percentage are used to describe the categorical variables, and the continuous variables were described by mean and standard deviation. Categorical variables were analyzed using Chisquared test. Continuous variables were analyzed using Student's $t$ test. Variables showing a $P$ value $<0.05$ in univariable analysis were considered as candidates for the multivariate Cox regression model, and a forward stepwise method was used to determine the final multivariable model. SPSS 19.0 was used for the statistical analysis.

\section{Results}

\section{Clinical characteristics of all patients}

By summarizing all admission and discharge records and following strict inclusion and exclusion criteria, a total of 409 COVID-19 patients were enrolled in this study (Figure 1). Among them, 48 were severe patients and 361 were non-severe patients. Of the 48 severe patients, 20 died as a result of exacerbations. The rest of the severe patients and all the non-severe patients recovered and were discharged from hospital. Figure 2 showed the discharge time or transfer time for each patient. The average age of all patients was $50.47 \pm 12.43$ years. The median duration of all patients was 23 (IQR 19-28) days. The main symptoms of the patient were fever $(95.6 \%)$ and cough $(74.3 \%)$, followed by tiredness $(21.5 \%)$, sputum $(18.1 \%)$, body aches $(15.6 \%)$ and diarrhea (7.8\%). Comorbidities were present in nearly half of the patients, mainly including hypertension $(30.6 \%)$ diabetes $(17.6 \%)$ and heart disease $(12.5 \%)$. CT signs of pulmonary infection were also present in almost half of the patients, $68.0 \%$ of whom showed ground-glass opacity and $60.6 \%$ which showed bilateral pulmonary infiltration (Table 2).

Table 2. Clinical characteristics of severe and non-severe COVID-19 patients

\begin{tabular}{|c|c|c|c|}
\hline Items & $\begin{array}{l}\text { All patients } \\
(\mathrm{n}=409)\end{array}$ & $\begin{array}{l}\text { Severe patients } \\
(\mathrm{n}=48)\end{array}$ & $\begin{array}{l}\text { Non-severe patients } \\
(\mathrm{n}=361)\end{array}$ \\
\hline \multicolumn{4}{|l|}{ Gender } \\
\hline Male & $188,46.0 \%$ & $24,50.0 \%$ & $164,45.4 \%$ \\
\hline Female & $221,54.0 \%$ & $24,50.0 \%$ & $197,54.6 \%$ \\
\hline Age & $50.47 \pm 12.43$ & $62.98 \pm 6.80$ & $48.80 \pm 12.05$ \\
\hline \multicolumn{4}{|l|}{ Disease type } \\
\hline Mild & $46,11.2 \%$ & $0,0 \%$ & $46,12.7 \%$ \\
\hline Common & $315,77.0 \%$ & $0,0 \%$ & $315,87.3 \%$ \\
\hline Severe & $48,11.8 \%$ & $48,100 \%$ & $0,0 \%$ \\
\hline \multicolumn{4}{|l|}{ Fever } \\
\hline Yes & $391,95.6 \%$ & $46,95.8 \%$ & $345,95.6 \%$ \\
\hline No & $18,4.4 \%$ & $2,4.2 \%$ & $16,4.4 \%$ \\
\hline \multicolumn{4}{|l|}{ Cough } \\
\hline Yes & $304,74.3 \%$ & $38,79.2 \%$ & $266,73.7 \%$ \\
\hline No & $105,25.7 \%$ & $10,20.8 \%$ & $95,26.3 \%$ \\
\hline \multicolumn{4}{|l|}{ Tiredness } \\
\hline Yes & $88,21.5 \%$ & $11,22.9 \%$ & $77,21.3 \%$ \\
\hline No & $321,78.5 \%$ & $37,77.1 \%$ & $284,78.7 \%$ \\
\hline \multicolumn{4}{|l|}{ Sputum } \\
\hline Yes & $74,18.1 \%$ & $10,20.8 \%$ & $64,17.7 \%$ \\
\hline No & $335,81.9 \%$ & $38,79.2 \%$ & $297,82.3 \%$ \\
\hline \multicolumn{4}{|l|}{ Body aches } \\
\hline Yes & $64,15.6 \%$ & $12,25.0 \%$ & $52,14.4 \%$ \\
\hline No & $345,84.4 \%$ & $36,75.0 \%$ & $309,85.6 \%$ \\
\hline \multicolumn{4}{|l|}{ Diarrhea } \\
\hline Yes & $32,7.8 \%$ & $9,18.8 \%$ & $23,6.4 \%$ \\
\hline No & $377,92.2 \%$ & $39,81.3 \%$ & $338,93.6 \%$ \\
\hline Number of symptoms & $2(1-5)$ & $3(1-4)$ & $2(1-5)$ \\
\hline \multicolumn{4}{|l|}{ Hypertension } \\
\hline Yes & $125,30.6 \%$ & $23,47.9 \%$ & $102,28.3 \%$ \\
\hline No & $284,69.4 \%$ & $25,52.1 \%$ & $259,71.7 \%$ \\
\hline \multicolumn{4}{|l|}{ Diabetes } \\
\hline Yes & $72,17.6 \%$ & $15,31.3 \%$ & $57,15.8 \%$ \\
\hline No & $337,82.4 \%$ & $33,68.8 \%$ & $304,84.2 \%$ \\
\hline \multicolumn{4}{|l|}{ Heart disease } \\
\hline Yes & $51,12.5 \%$ & $9,18.8 \%$ & $42,11.6 \%$ \\
\hline No & $358,87.5 \%$ & $39,81.3 \%$ & $319,88.4 \%$ \\
\hline \multicolumn{4}{|l|}{ Pulmonary disease } \\
\hline Yes & $17,4.2 \%$ & $4,8.3 \%$ & $13,3.6 \%$ \\
\hline No & $392,95.8 \%$ & $44,91.7 \%$ & $348,96.4 \%$ \\
\hline \multicolumn{4}{|l|}{ Other comorbidities } \\
\hline Yes & $57,13.9 \%$ & $9,18.8 \%$ & $48,13.3 \%$ \\
\hline No & $352,86.1 \%$ & $39,81.3 \%$ & $313,86.7 \%$ \\
\hline \multicolumn{4}{|l|}{ CT ground-glass opacity } \\
\hline Yes & $278,68.0 \%$ & $39,81.3 \%$ & $239,66.2 \%$ \\
\hline No & $131,32.0 \%$ & $9,18.8 \%$ & $122,33.8 \%$ \\
\hline \multicolumn{4}{|c|}{ CT bilateral pulmonary infiltration } \\
\hline Yes & $248,60.6 \%$ & $36,75.0 \%$ & $212,58.7 \%$ \\
\hline No & $161,39.4 \%$ & $12,25.0 \%$ & $149,41.3 \%$ \\
\hline Disease duration & $23(19-28)$ & $37(32-43)$ & $22(19-26)$ \\
\hline
\end{tabular}




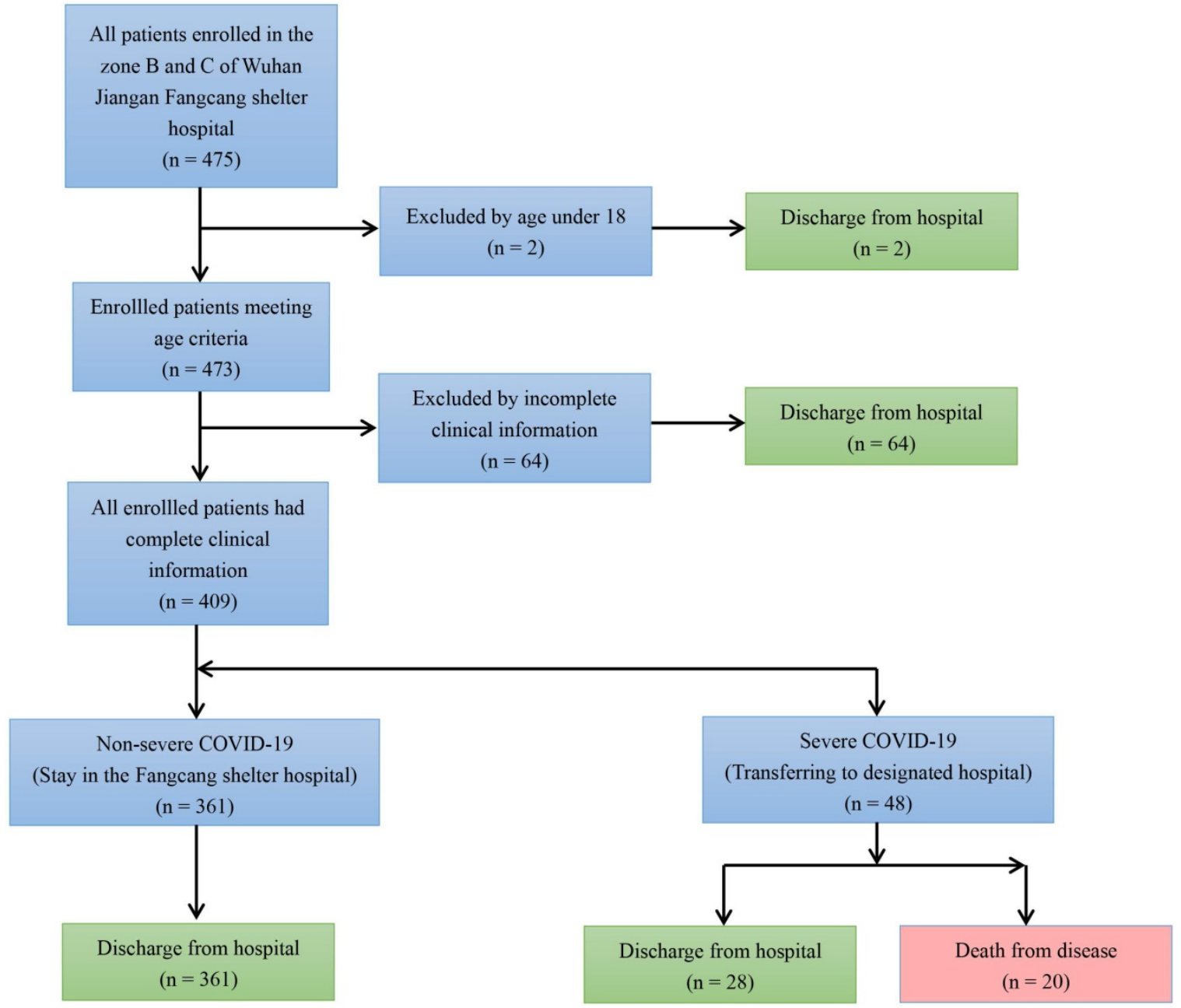

Figure 1. Flow diagram.

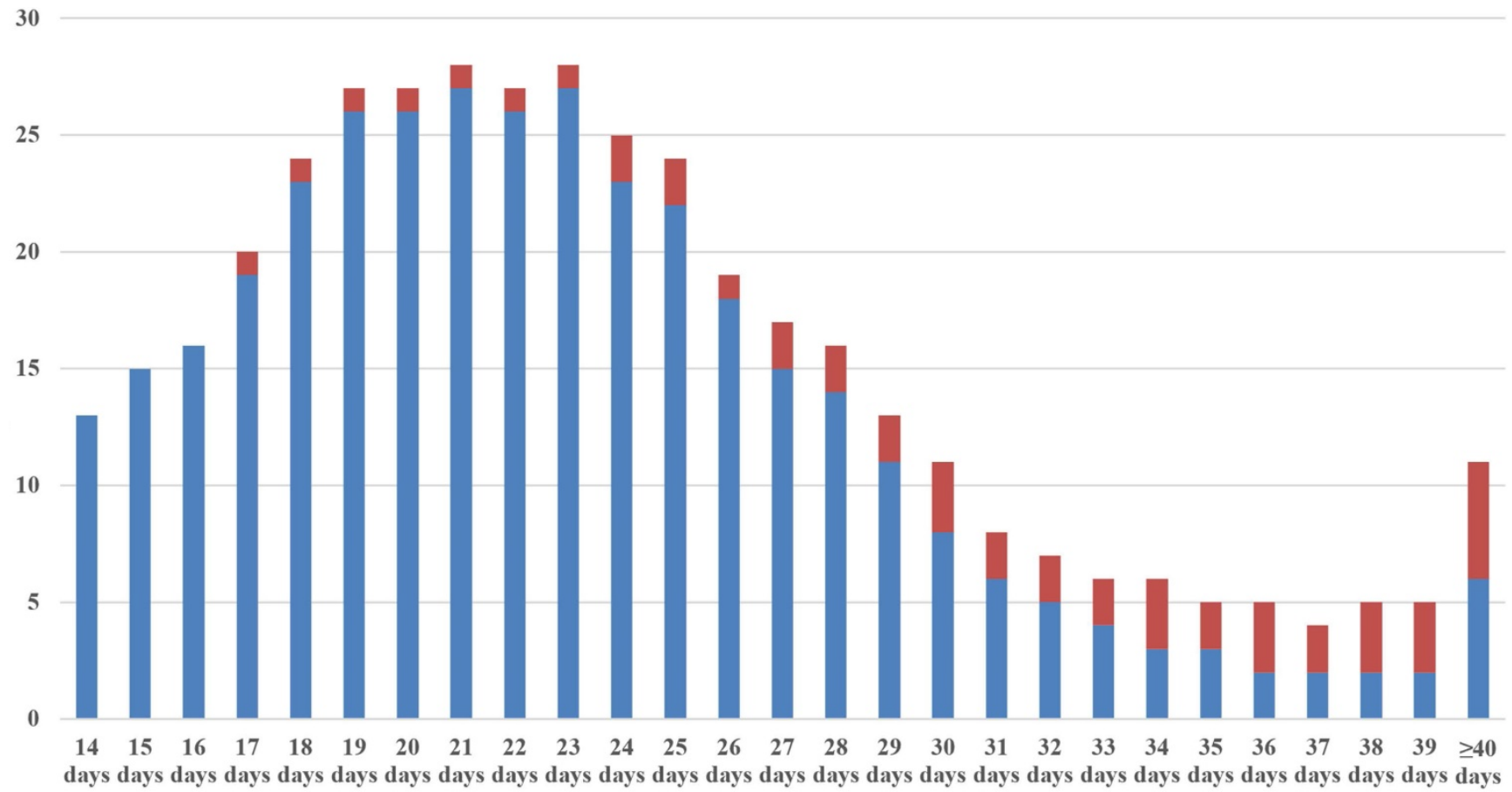

Enon-severe $\quad$ Transfer to a superior hospital

Figure 2. The distribution of discharge time or transfer time for each patient. 


\section{The risk factors for non-severe to severe COVID-1 9 (including death)}

Univariate Cox regression analysis indicated that old age (HR: 4.522; 95\% CI: 1.067-19.168; P $=0.041$ ), the number of symptoms (HR: 2.055; 95\% CI: 1.091-3.871; $\mathrm{P}=0.026)$, the combination of hypertension (HR: 2.544; 95\% CI: 1.389-4.659; $\mathrm{P}=$ 0.002), heart disease (HR: 2.220; 95\% CI: 1.212-4.065; P $=0.010)$, pulmonary disease (HR: 2.114; 95\% CI: 1.070-4.179; $\mathrm{P}=0.031$ ) and other comorbidities (HR: 1.838; 95\% CI: $1.006-3.360 ; \mathrm{P}=0.048$ ) were the risk factors for the progression from non-severe to severe COVID-19 (including death) (Table 3). Multivariate Cox regression analysis showed that old age (HR: 7.294; 95\% CI: 1.442-36.888; $\mathrm{P}=0.016)$, the combination of hypertension (HR: 2.230; 95\% CI: 1.090-4.562; $\mathrm{P}=0.028$ ) and heart disease (HR: 2.650; 95\% CI: 1.079-6.510; P = 0.034) were independent risk factors for progression from non-severe to severe COVID-19 (including death) (Table 3).

Table 3. Univariate and multivariate Cox regression survival analysis of risk factor for progression to severe COVID-19

\begin{tabular}{|c|c|c|c|c|c|c|}
\hline \multirow[t]{2}{*}{ Items } & \multicolumn{3}{|c|}{ Univariate analysis } & \multicolumn{3}{|c|}{ Multivariate analysis } \\
\hline & $\overline{\mathrm{HR}}$ & HR.95\% CI & $P$ & HR & HR.95\% CI & $P$ \\
\hline Age (>50 vs. $\leq 50)$ & 4.522 & $1.067-19.168$ & $0.041^{*}$ & 7.294 & $1.442-36.888$ & $0.016^{*}$ \\
\hline Fever (Yes vs. No) & 1.391 & $0.331-5.837$ & 0.652 & 0.614 & $0.109-3.488$ & 0.579 \\
\hline Cough (Yes vs. No) & 1.251 & $0.621-2.520$ & 0.531 & 1.327 & $0.523-3.366$ & 0.551 \\
\hline Sputum (Yes vs. No) & 1.524 & $0.833-2.790$ & 0.172 & 1.734 & $0.778-3.865$ & 0.178 \\
\hline Tiredness (Yes vs. No) & 1.125 & $0.625-2.026$ & 0.694 & 0.606 & $0.237-1.551$ & 0.297 \\
\hline Body aches (Yes vs. No) & 1.949 & $0.994-3.822$ & 0.052 & 2.403 & $0.962-6.007$ & 0.061 \\
\hline Diarrhea (Yes vs. No) & 1.570 & $0.751-3.283$ & 0.231 & 1.822 & $0.716-4.634$ & 0.208 \\
\hline $\begin{array}{l}\text { Number of symptoms } \\
(>3 \text { vs. } \leq 3)\end{array}$ & 2.055 & $1.091-3.871$ & $0.026^{*}$ & 2.500 & $0.676-9.241$ & 0.170 \\
\hline $\begin{array}{l}\text { Hypertension } \\
\text { (Yes vs. No) }\end{array}$ & 2.544 & $1.389-4.659$ & $0.002^{*}$ & 2.230 & $1.090-4.562$ & $0.028^{*}$ \\
\hline Diabetes (Yes vs. No) & 1.291 & $0.698-2.388$ & 0.416 & 1.548 & $0.739-3.240$ & 0.246 \\
\hline $\begin{array}{l}\text { Heart disease } \\
\text { (Yes vs. No) }\end{array}$ & 2.220 & $1.212-4.065$ & $0.010^{*}$ & 2.650 & $1.079-6.510$ & $0.034^{*}$ \\
\hline $\begin{array}{l}\text { Pulmonary disease } \\
\text { (Yes vs. No) }\end{array}$ & 2.114 & $1.070-4.179$ & $0.031^{*}$ & 0.858 & $0.327-2.249$ & 0.755 \\
\hline $\begin{array}{l}\text { Other comorbidities } \\
\text { (Yes vs. No) }\end{array}$ & 1.838 & $1.006-3.360$ & $0.048^{*}$ & 1.027 & $0.510-2.069$ & 0.941 \\
\hline $\begin{array}{l}\text { CT ground-glass } \\
\text { opacity (Yes vs. No) }\end{array}$ & 1.272 & $0.525-3.084$ & 0.594 & 0.955 & $0.367-2.487$ & 0.925 \\
\hline $\begin{array}{l}\text { CT bilateral pulmonary } \\
\text { infiltration (Yes vs. No) }\end{array}$ & 1.199 & $0.618-2.327$ & 0.592 & 1.044 & $0.495-2.203$ & 0.909 \\
\hline
\end{tabular}

\section{Discussion}

Wuhan was the epicentre of COVID-19 in China and around the world, in which the confirmed cases accounted for $80 \%$ of China's confirmed cases. At the height of the outbreak, the Chinese government quickly set up 16 Fangcang shelter hospitals in Wuhan. Fangcang shelter hospital refers to a novel concept: large, temporary hospitals built by converting public venues, such as stadiums and exhibition centres, into health-care facilities to isolate patients with non-severe novel coronavirus patients
[8]. Since non-severe patients accounted for $80 \%$ of the total number of patients, Fangcang shelter hospitals isolated thousands of patients, provided high-quality medical treatment and care, and fulfilled an important triage function. However, there are also a considerable number of COVID-19 patients under severe or even critical condition complicated with severe pneumonia, acute respiratory distress syndrome, acute respiratory failure or multiple organ failure. It is crucial to identify these high-risk group patients. So, we reported on a single-institution summary about non-severe patients in Wuhan Jiangan Fangcang shelter hospital, with emphasis on the risk factors affecting the disease progression of COVID-19.

Our study showed that old age, hypertension and heart disease were independent risk factors for progression from non-severe to severe COVID-19 (including death). Wang et al. 's study [10] showed that male, elder age, diabetes cardiovascular diseases, chills, dyspnea, $\mathrm{SO}_{2}$ value of $\leq 93 \%$, WBC counts of $>10 \times 10^{9} / \mathrm{L}$ and large consolidated opacity on CT images were all risk factors for aggravation of illness. Edith Sepulchre et al. [11] found that older age, male gender, comorbidities and dyspnea at admission constituted significantly worse prognosis factors. Feng $\mathrm{He}$ et al. [12] found that older age, Wuhan exposure history, diarrhea, chronic kidney disease, elevated myoglobin, elevated white blood cell and C-reactive protein were independent risk factors for severe patients with COVID-19.

A meta-analysis about clinical data of COVID-19 involving 10 epidemiology studies showed that the discharge rate of COVID-19 patients was about 52\%, and the fatality rate was about 5\% [13]. In our Fangcang shelter hospitals, 48 patients were transferred to superior hospitals due to worsening conditions, and 20 of them died in critical condition. The mortality of COVID-19 was $4.89 \%$ which was similar to the result of meta-analysis. However, it is remarkable that all of non-severe patients in our and wang et al.'s [10] study was discharged from the Fangcang shelter hospitals, and none died. So, we have enough confidence to cure the non-severe patient. The most difficult task is to treat the severe patient, especially in the absence of evidence supporting an effective drug. Therefore, it is important to identify patients who have the potential to develop severe disease. Early recognition of severe infection may allow early intervention with supportive measures and therapeutics and improve outcomes [14].

First of all, we should pay attention to the age of patients. On the one hand, elderly patients had poor immunity compared with younger patients; on the 
other hand, elderly patients were more likely to have other comorbidities. Therefore, it was not difficult to understand that old age was one of the factors affecting the course of disease [15]. A retrospective study of older COVID-19 patients showed that patients who were 65 years and older, the mortality rate was $34.5 \%(19 / 55)$, which was significantly higher than that of younger patients at $4.7 \%(7 / 148)$. And compared with young patients, older patients had more laboratory abnormalities and comorbidities [16]. Therefore, monitoring and supportive treatment of elderly patients should be strengthened.

Second, the number of co-existing symptoms was also correlated with the patients' disease progression and this concept first proposed and discovered in our study. When there were many kinds of symptoms in patients, it meant that the virus load in patients was large, which had seriously affected multiple body systems, not only respiratory system. At this time, the rehabilitation process of the patients needed a long time. With the slow recovery of all systems in the whole body, patients can achieve normal healing, so the course of the patients was prolonged. Therefore, emphasis should be placed on symptomatic and supportive treatment. The relief of objective symptoms was not only beneficial to overcome the disease, but also can enhance patients' confidence, reduce patients' discomfort, anxiety and fear.

Finally, we should pay more attention to the patients with multiple comorbidities, such as hypertension, diabetes, heart disease, pulmonary disease and other comorbidities. Moreover, many studies have shown that patients with these complications were more difficult to treat, more likely to develop disease aggravation, and more likely to lead to death $[4,10,16-22]$. This was similar to MERS-CoV [23]. Angiotensin converting enzyme 2 (ACE2) was the gateway to SARS-CoV-1 and SARS-CoV-2 [24,25]. The association between ACE2 expression and angiocardiopathy was confirmed in previous studies [26-28]. This partly explained why hypertension and heart disease may affect the progression of COVID-19. Furthermore, it was well known that high level of renin-angiotensin (RAS) is an important cause of hypertension. In a mouse model, activation of RAS can lead to lung injury [24]. It was reasonable to suspect that COVID-19 exacerbated lung injury in patients with hypertension and heart disease by further activating RAS. Diabetes was another risk factor for the prognosis of COVID-19. Patients with diabetes generally have higher mortality and morbidity to infectious diseases. It may be possibly due to chronic immune system imbalances, metabolic syndrome, or excess nutrition caused by obesity. On the other side, some viruses were diabetogenic themselves [29]. A study of SARS found that even non-severe patients who had not received glucocorticoid therapy had higher levels of fasting blood glucose [30]. Therefore, one study has suggested that diabetes with SARS-CoV-2 pneumonia may form a vicious circle, which was not conducive to the prognosis of COVID-19 [22].

This study has some limitations. First of all, this study was a retrospective cohort study, lacking the validation of prospective studies. Secondly, when we collected data, a large proportion of patients are excluded due to the lack of relevant clinical data, which may lead to potential selection bias. Finally, due to the limitations of the facilities in Fangcang shelter hospital, routine blood and biochemical tests were not performed on all patients during their hospitalization. Therefore, there is a lack of patients' laboratory examinations. According to the results of previous studies, some laboratory indicators may also be risk factors for the prognosis of patients $[17,31]$.

\section{Conclusion}

Patients with older age, hypertension, and heart disease were more likely to deteriorate into severe COVID-19 or even death. These risk factors, as early warning indicators, can alert careful observation and early intervention to prevent disease progression and reduce mortality.

\section{Abbreviations}

COVID 19: coronavirus disease 2019; SARSCoV-2: severe acute respiratory syndrome coronavirus 2; ACE2: Angiotensin converting enzyme 2; RAS: renin-angiotensin.

\section{Acknowledgments}

We thank the health workers of Tianjin medical team and all other people working in and supporting the Jiangan Fangcang shelter hospitals in Wuhan, China. We also thank all the patients included in this study.

\section{Contributors}

Zhengtong Lv was responsible for study design, data analysis and article writing. Shubin Lv was responsible for data collection and financial support.

\section{Competing Interests}

The authors have declared that no competing interest exists.

\section{References}

1. Phelan AL, Katz R, Gostin LO. The Novel Coronavirus Originating in Wuhan, China: Challenges for Global Health Governance. JAMA. 2020; 323: 709-710. 
2. Chen L, Liu $\mathrm{W}$, Zhang $\mathrm{Q}, \mathrm{Xu} \mathrm{K}, \mathrm{Ye} \mathrm{G}, \mathrm{Wu} \mathrm{W}$, et al. RNA based mNGS approach identifies a novel human coronavirus from two individual pneumonia cases in 2019 Wuhan outbreak. Emerg Microbes Infect. 2020; 9: 313-9.

3. Huang C, Wang Y, Li X, Ren L, Zhao J, Hu Y, et al. Clinical features of patients infected with 2019 novel coronavirus in Wuhan, China. Lancet. 2020; 395: 497-506.

4. Chen N, Zhou M, Dong X, Qu J, Gong F, Han Y, et al. Epidemiological and clinical characteristics of 99 cases of 2019 novel coronavirus pneumonia in Wuhan, China: a descriptive study. Lancet. 2020; 395: 507-13.

5. Guan WJ, Ni ZY, Hu Y, Liang WH, Ou CQ, He JX, et al. Clinical Characteristics of Coronavirus Disease 2019 in China. N Engl J Med. 2020; 382: 1708-1720.

6. Xie J, Tong Z, Guan X, Du B, Qiu H. Clinical Characteristics of Patients Who Died of Coronavirus Disease 2019 in China. JAMA Netw Open. 2020; 3: e205619.

7. The epidemiological characteristics of an outbreak of 2019 novel coronavirus diseases (COVID-19) in China. Zhonghua Liu Xing Bing Xue Za Zhi. 2020; 41: 145-51.

8. Chen S, Zhang Z, Yang J, Wang J, Zhai X, Barnighausen T, et al. Fangcang shelter hospitals: a novel concept for responding to public health emergencies. Lancet. 2020; 395: 1305-1314.

9. Peduzzi P, Concato J, Kemper E, Holford TR, Feinstein AR. A simulation study of the number of events per variable in logistic regression analysis. Journal of clinical epidemiology. 1996; 49: 1373-9.

10. Wang X, Fang J, Zhu Y, Chen L, Ding F, Zhou R, et al. Clinical characteristics of non-critically ill patients with novel coronavirus infection (COVID-19) in a Fangcang Hospital. Clinical microbiology and infection: the official publication of the European Society of Clinical Microbiology and Infectious Diseases. 2020; 26: 1063-1068.

11. Sepulchre E, Pittie G, Stojkovic V, Haesbroek G, Crama Y, Schyns M, et al. Covid-19: contribution of clinical characteristics and laboratory features for early detection of patients with high risk of severe evolution. Acta Clin Belg. 2020: 1-7.

12. He F, Luo $Q$, Lei M, Fan L, Shao X, Huang G, et al. Risk factors for severe cases of COVID-19: a retrospective cohort study. Aging (Albany NY). 2020; 12: 15730-40.

13. Li LQ, Huang T, Wang YQ, Wang ZP, Liang Y, Huang TB, et al. COVID-19 patients' clinical characteristics, discharge rate, and fatality rate of meta-analysis. J Med Virol. 2020; 92: 577-583.

14. Zhang JJY, Lee KS, Ang LW, Leo YS, Young BE. Risk Factors of Severe Disease and Efficacy of Treatment in Patients Infected with COVID-19: A Systematic Review, Meta-Analysis and Meta-Regression Analysis. Clin Infect Dis. 2020.

15. Wang D, Hu B, Hu C, Zhu F, Liu X, Zhang J, et al. Clinical Characteristics of 138 Hospitalized Patients With 2019 Novel Coronavirus-Infected Pneumonia in Wuhan, China. JAMA. 2020; 323: 1061-1069.

16. Chen T, Dai Z, Mo P, Li X, Ma Z, Song S, et al. Clinical characteristics and outcomes of older patients with coronavirus disease 2019 (COVID-19) in Wuhan, China (2019): a single-centered, retrospective study. J Gerontol A Biol Sci Med Sci. 2020; 75: 1788-1795.

17. Li X, Xu S, Yu M, Wang K, Tao Y, Zhou Y, et al. Risk factors for severity and mortality in adult COVID-19 inpatients in Wuhan. J Allergy Clin Immunol. 2020; 146: 110-118.

18. Mo P, Xing Y, Xiao Y, Deng L, Zhao Q, Wang H, et al. Clinical characteristics of refractory COVID-19 pneumonia in Wuhan, China. Clin Infect Dis. 2020.

19. Deng $Y$, Liu W, Liu K, Fang YY, Shang J, Zhou L, et al. Clinical characteristics of fatal and recovered cases of coronavirus disease 2019 (COVID-19) in Wuhan, China: a retrospective study. Chin Med J (Engl). 2020; 133: 1261-1267.

20. Li X, Wang L, Yan S, Yang F, Xiang L, Zhu J, et al. Clinical characteristics of 25 death cases with COVID-19: a retrospective review of medical records in a single medical center, Wuhan, China. Int J Infect Dis. 2020; 94: 128-132.

21. Zheng F, Tang W, Li H, Huang YX, Xie YL, Zhou ZG. Clinical characteristics of 161 cases of corona virus disease 2019 (COVID-19) in Changsha. Eur Rev Med Pharmacol Sci. 2020; 24: 3404-10.

22. Guo W, Li M, Dong Y, Zhou H, Zhang Z, Tian C, et al. Diabetes is a risk factor for the progression and prognosis of COVID-19. Diabetes Metab Res Rev. 2020: e3319.

23. Badawi A, Ryoo SG. Prevalence of comorbidities in the Middle East respiratory syndrome coronavirus (MERS-CoV): a systematic review and meta-analysis. Int J Infect Dis. 2016; 49: 129-33.

24. Kuba K, Imai Y, Rao S, Gao H, Guo F, Guan B, et al. A crucial role of angiotensin converting enzyme 2 (ACE2) in SARS coronavirus-induced lung injury. Nat Med. 2005; 11: 875-9.

25. Dimitrov DS. The secret life of ACE2 as a receptor for the SARS virus. Cell. 2003; 115: 652-3.

26. Li S, Wang Z, Yang X, Hu B, Huang Y, Fan S. Association between circulating angiotensin-converting enzyme 2 and cardiac remodeling in hypertensive patients. Peptides. 2017; 90: 63-8.

27. Goulter $\mathrm{AB}$, Goddard MJ, Allen JC, Clark KL. ACE2 gene expression is up-regulated in the human failing heart. BMC Med. 2004; 2: 19.

28. Crackower MA, Sarao R, Oudit GY, Yagil C, Kozieradzki I, Scanga SE, et al. Angiotensin-converting enzyme 2 is an essential regulator of heart function. Nature. 2002; 417: 822-8.

29. Jaeckel E, Manns M, Von Herrath M. Viruses and diabetes. Ann N Y Acad Sci. 2002; 958 .
30. Yang JK, Feng Y, Yuan MY, Yuan SY, Fu HJ, Wu BY, et al. Plasma glucose levels and diabetes are independent predictors for mortality and morbidity in patients with SARS. Diabet Med. 2006; 23: 623-8.

31. Liu Y, Du X, Chen J, Jin Y, Peng L, Wang HHX, et al. Neutrophil-tolymphocyte ratio as an independent risk factor for mortality in hospitalized patients with COVID-19. The Journal of infection. 2020; 81: e6-e12. 